\title{
The Framework Convention on Tobacco Control: opportunities and issues
}

\author{
Kenneth E Warner, PhD.(I)
}

\begin{abstract}
Warner KE.
The Framework Convention

on Tobacco Control: opportunities and issues. Salud Publica Mex 2008;50 suppl 3:S283-S29I.
\end{abstract}

\begin{abstract}
The Framework Convention on Tobacco Control (FCTC), a World Health Organization sponsored global tobacco control treaty, constitutes the first major international tool with the potential to significantly reduce the global pandemic of tobacco-produced disease and death. After providing background on the prevalence of cigarette smoking and smoking attributable mortality, both at present and projected for the future, the paper then describes the FCTC and discusses its development, the barriers it has confronted, and the opportunities it offers for improving global health. Successful implementation of the provisions in the treaty could avoid literally tens of millions of premature tobacco-produced deaths over the next few decades.
\end{abstract}

Key words: smoking; tobacco control; treaty; Framework Convention on Tobacco Control

\section{Warner KE.}

El Convenio Marco para el Control

del Tabaco: oportunidades y problemas.

Salud Publica Mex 2008;50 supl 3:S283-S29I.

\section{Resumen}

El Convenio Marco para el Control del Tabaco (CMCT), un tratado para el control global del tabaco patrocinado por la Organización Mundial de la Salud, constituye la primera herramienta internacional importante con el potencial de reducir significativamente la pandemia mundial de enfermedades y decesos producidos por el tabaco. Este ensayo proporciona antecedentes sobre la prevalencia de consumo de cigarrillos y sobre mortalidad atribuible a dicho consumo, tanto al presente como con proyección a futuro. Después describe el CMCT, su desarrollo, las barreras que ha confrontado y las oportunidades que ofrece para mejorar la salud global. La implementación exitosa de las disposiciones del tratado podría evitar, literalmente, decenas de millones de muertes prematuras producidas por el tabaco en las próximas décadas.

Palabras clave: tabaquismo; control del tabaco; tratado; Convenio Marco para el Control del Tabaco
L ong a plague among the world's affluent nations, cigarette smoking is increasingly the source of death and devastation in middle income and developing countries as well. In recent years a powerful new tool has become available to address the toll of tobacco: the Framework Convention on Tobacco Control (FCTC) ${ }_{1}^{1}$ a
World Health Organization sponsored global tobacco control treaty. This paper opens with context addressing the need for the treaty, providing background on the prevalence of cigarette smoking and smoking attributable mortality, both at present and projected for the future, with specific reference to the prevalence of smok-

(I) Dean \& Avedis Donabedian Distinguished University Professor of Public Health, School of Public Health. University of Michigan, USA. 
ing in Mexico. The bulk of the paper is then devoted to describing the FCTC and discussing its development, the barriers it has confronted, and the opportunities it offers for improving global health.

\section{Background}

Smoking prevalence

Worldwide some 5.6 trillion cigarettes are consumed annually, nearly 900 for every man, woman, and child. In those countries for which data are available, per capita cigarette consumption -total cigarette consumption divided by the population- ranged from 53 in Ethiopia to 3441 in Bulgaria. ${ }^{2}$ In Mexico, per capita consumption stood at 733 a figure that, impressively, has halved since $1980 .^{3}$

Almost one billion men smoke around the world. In developed countries, an average of 35 percent of men are smokers. In developing countries, the average is 50 percent. There are over 300 million male smokers in China alone. Two hundred and fifty million women are smokers worldwide. At present, 22 percent of women in developed countries smoke, while in developing countries the figure is only 9 percent. ${ }^{2}$ In Mexico, in 1998, data indicate that nearly 43 percent of males were smokers, while 16 percent of females smoked, for a total smoking prevalence of 27.4 percent. Among adults, age 18-65, over half of all men smoked, while just under a fifth of women smoked. It is notable, if discouraging, that over a fifth of all physicians in Mexico -22 percent- were smokers $^{3}$ (Table I).

The World Health Organization projects that the number of smokers worldwide will increase from 1.25 billion today to about 1.7 billion in two decades. ${ }^{4}$ This increase will primarily reflect population growth, but it will also represent a continuing shift in the smoking population from the developed nations, where smoking prevalence is declining, to developing countries, in many of which it is increasing. Growth will be far more substantial among women than man, especially in developing countries.

\section{Smoking-produced mortality}

Each year cigarette smoking kills 5 million people, onehalf of them during their working age years (35-69). ${ }^{4}$ While lung cancer is the most feared consequence of smoking, the behavior claims a roughly equal number of lives as a result of cardiovascular disease. It is also the leading cause of death attributable to chronic obstructive pulmonary disease. ${ }^{5}$ The importance of smoking in national mortality statistics is illustrated by the fact
Table I

Smoking Prevalence in Mexico, 1998

\begin{tabular}{lccc} 
Group & $M(\%)$ & $F(\%)$ & Total (\%) \\
All & 42.9 & 16.3 & 27.4 \\
\hline Adults, I8-65 & 51.2 & 18.4 & 32.0 \\
\hline Youth & 26.7 & 16.2 & 21.7 \\
\hline Physicians & & & 22.0 \\
\hline Medical staff & & & 24.0
\end{tabular}

Source: World Health Organization. 2007. Mexico

http://www.who.int/tobacco/media/en/Mexico.pdf <accessed December 13, 2007>

that, in the United States, lung cancer was a virtually unheard of disease in the early 1900s. At present, it is the leading cause of cancer mortality in both men and women, and epidemiologic research indicates that as much as 90 percent of lung cancer deaths would not occur in the absence of smoking. ${ }^{5}$ While many think of the adverse health consequences of smoking as a developed country problem, more than half of smoking-related deaths today occur in developing countries. ${ }^{4}$

As a consequence of the projected increases in global smoking, smoking-related deaths are predicted by WHO to increase to about 10 million per year roughly less than two decades from now. ${ }^{4}$ At that time, 70 percent of those deaths will occur in developing countries. Cigarette smoking will then be the leading avoidable behavioral cause of death throughout the world.

\section{Temporal pattern of smoking and smoking-produced} mortality within a country

Figure 1 is a conceptual schema depicting the typical spread of smoking and smoking-related mortality within a developed country over time. ${ }^{6}$ It is important to emphasize that the figure is merely a characterization of the typical experience to date. The pattern is not preordained or inevitable. It is useful primarily for understanding where a country stands in the evolution of its own smoking epidemic and hence providing benchmarks for progress in combating it. In those countries where it remains possible, the goal, of course, is to short-circuit both the spread of smoking and its inevitable trail of disease and death.

The figure shows four stages in the smoking epidemic. During the first stage, the beginning of the epidemic, smoking among men starts to rise rapidly. There is little smoking among women, and little mortality as 


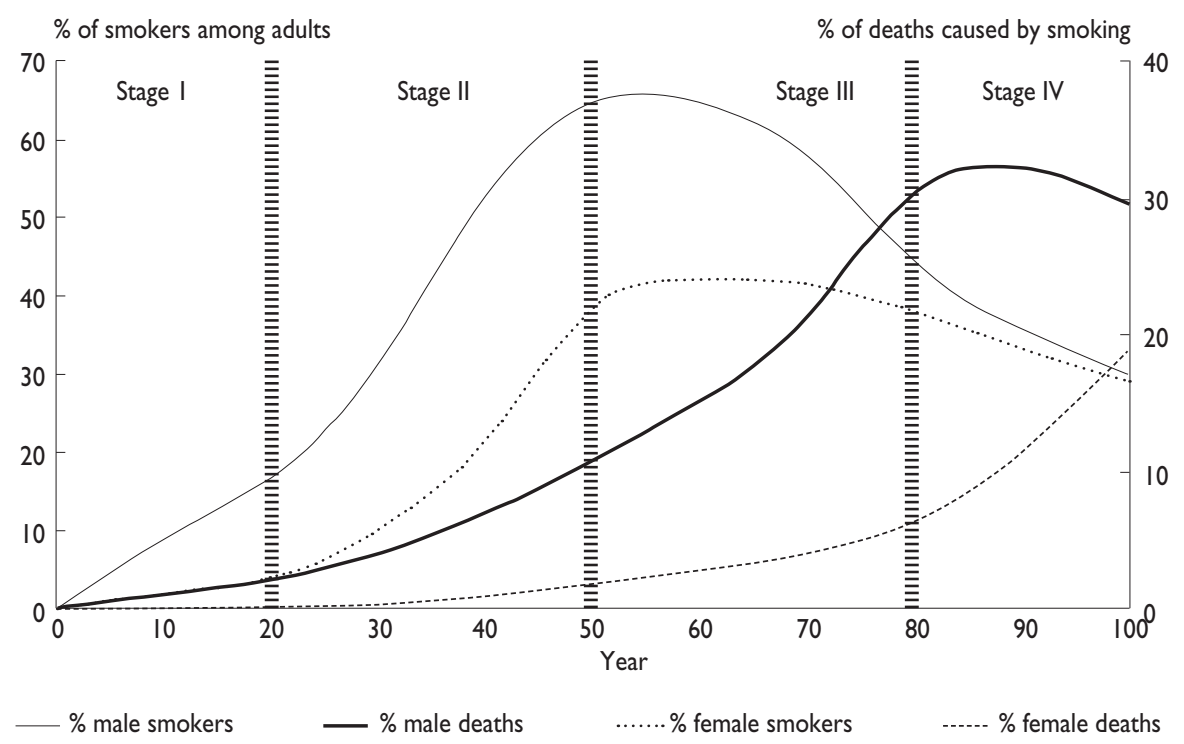

Source: Lopez AD, Collishaw NE, Piha T. A descriptive model of the cigarette epidemic in developed countries. Tobacco Control. 1994;3:242-247

Figure I. SPREAd OF SMOKING AND SMOKING-RELATEd MORTALITY WITHIN A COUNTRY, OVER TIME

a result of the fact that smoking is relatively new. In the figure, the first stage lasts about 20 years.

In the second stage, smoking among men continues to climb fairly rapidly, although eventually at a decelerating rate, reaching what ultimately becomes the peak smoking prevalence among males at something in access of 60 percent. Smoking among women starts to rise rapidly during this period as well, reaching as much as 30 to 35 percent. Mortality as a result of smoking begins a long and sustained increase to the point where, by the end of the second stage, some 10 percent of a country's total deaths may be caused by smoking. This second stage lasts about 30 years.

In the third stage, male smoking, having peaked, begins a steady decline. By the end of this stage, which also takes about 30 years, male smoking will have dropped to about 25 percent of all men, having more than halved. Smoking prevalence among women flattens during this period and then begins a gradual decline. However, the decline is much less rapid than that of men, meaning that the prevalence of smoking among males begins to approach that of females by the end of this stage. Mortality has increased significantly for both men and women.

In the fourth stage, estimated to last about 20 years, male smoking declines to something under 20 percent, as does female smoking, at which point men and women smoke at virtually identical rates. Male smoking-related mortality declines as well, while female smoking-related mortality continues to increase, the result of the later adoption of smoking by large numbers of women and their more gradual rate of cessation. Smoking now accounts for close to a quarter of a nation's total mortality.

Although this model does not apply precisely to all countries, it is an important demonstration of a general pattern that has applied in many. Note that no country has as yet experienced a fifth, or perhaps sixth, stage in which smoking becomes a rare phenomenon and the death toll associated with the behavior becomes of limited significance in overall mortality statistics. Those are the goals of tobacco control worldwide.

\section{Background on the Framework Convention on Tobacco Control}

\section{Nature of a framework convention}

The Framework Convention on Tobacco Control (FCTC) represents the World Health Organization's first-ever use of its long standing authority to create a global public health treaty. ${ }^{1} \mathrm{~A}$ framework convention is a treaty that creates a set of principles and general duties for nations to address in a broad subject area, like tobacco 
use. As the name suggests, it creates a framework for approaching a problem. Specific requirements of the nations that ratify the convention are then fleshed out through negotiation of detailed "protocols" after countries have ratified the convention. As such, a framework convention stands in contrast to a conventional treaty in which the specific requirements of the members are specified quite precisely prior to ratification.

An example of a well-known framework convention is the Framework Convention on Climate Change, which established a framework for addressing global warming. The Kyoto Protocol created specific binding rules on the member nations that had ratified the convention.

\section{Objective}

The objective of the FCTC, codified in Article 3, is the following: " $[\mathrm{T}]$ o protect present and future generations from the devastating health, social, environmental and economic consequences of tobacco consumption and exposure to tobacco smoke by providing a framework for tobacco control measures [...] to reduce continually and substantially the prevalence of tobacco use and exposure to tobacco smoke". ${ }^{7}$ The convention encourages three principal types of strategies:

1) a public health approach that seeks to change the social climate and promote a supportive environment for smoking cessation and non-initiation;

2) a health systems approach that focuses on promoting and integrating clinical best practices (behavioral and pharmacological) that help tobacco-dependent consumers increase their chance of quitting successfully;

3) a surveillance, research, and information approach that promotes the exchange of information and knowledge so as to increase awareness of specific tobacco control needs, as well as the need to change social norms.

\section{History}

The idea underlying development of a framework convention on tobacco control originated around 1994 and was introduced at the World Health Assembly in May 1995. The following year, the $49^{\text {th }}$ WHA passed a resolution asking the Director-General of WHO to initiate development of a WHO Framework Convention on Tobacco Control. In 1998, soon after Dr. Gro Harlem Brundtland assumed the office of Director General of WHO, the Framework Convention was made a WHO leadership priority. In 1999-2000, informal working groups laid out the process by which the convention would be developed. Formal negotiations among the world's countries occurred from 2000-2003, with delegates meeting twice annually in Geneva for periods ranging from ten days to two weeks. In May 2003, the World Health Assembly approved the FCTC, with the 168 member countries present signing.

From 2003 to the present, ratification by individual countries has taken place. The treaty entered into force as a binding treaty on February 27, 2005, at which time 65 countries had ratified. Forty were required to make the treaty effective. The FCTC is one of the most rapidly and widely embraced UN treaties in history. As of April 102008 , 154 countries had ratified the Framework Convention. Mexico was among the early members, having ratified on May 28, 2004. Figure 2 shows the countries in the Americas that have ratified the treaty and those that have signed but thus far not yet ratified it. For a list of countries that have and have not ratified, go to http://www.fctc.org/index.php.

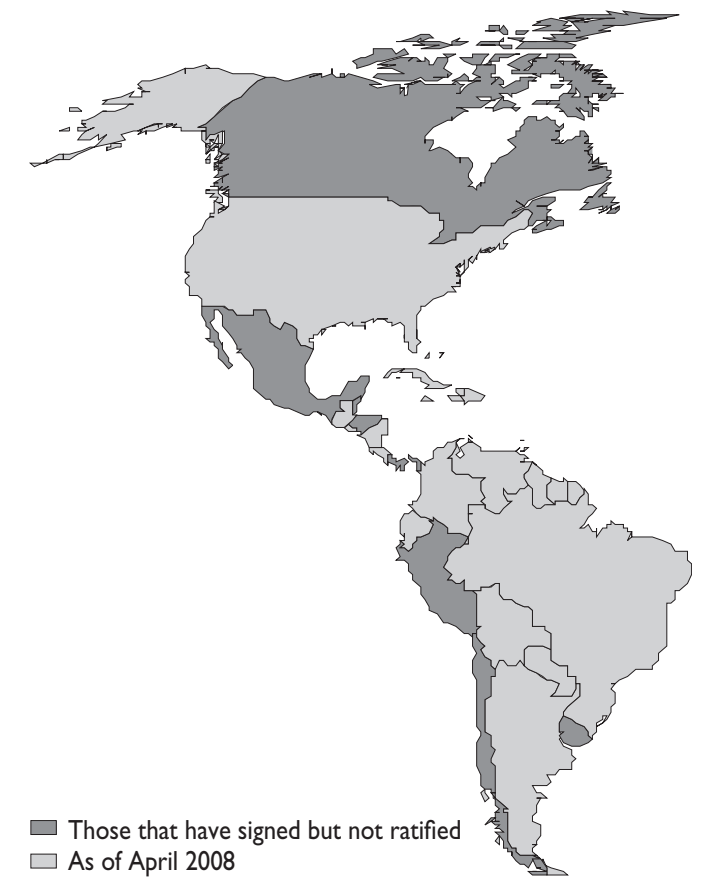

Source: Framework Convention Alliance for Tobacco Control. 2007. Ratification status by region. Available on: http://www.fctc.org/index.php?item=c ountryinfo\&region=2\&ratif=yes (accessed December 13, 2007).

Figure 2. Countries in the Americas that have ratified THE FCTC 
According to treaty provisions, by February 27, 2008 , the 40 original ratifying countries must have health warnings with specific characteristics on all packages of cigarettes. Two years later, by February 27, 2010, the 40 original countries must have banned advertising and promotion of tobacco products.

Beginning in February 2006, the countries that have ratified the FCTC met in the first meeting of what is known as the Conference of the Parties (COP) to negotiate specific protocols. The COP is the supreme organ of the Convention. It is empowered to adopt amendments to the FCTC, to adopt protocols or annexes, and to provide overall policy guidance for implementation. All Parties to the FCTC are automatically members of the $\mathrm{COP}$ with voting rights.

COP I took place in Geneva from February 7-16, 2006. At COP I, the Parties created working groups to begin development of protocols regarding cross border advertising and illicit trade; agreed to develop (nonbinding) guidelines on smoke-free policies and tobacco product regulation; developed a pilot reporting questionnaire; and agreed to establish an expert group regarding the idea of encouraging alternative crops to tobacco. ${ }^{8}$

COP II met in Bangkok from June 30-July 6, 2007. At COP II, the parties adopted a 100 percent smokefree guideline and agreed to start work on guidelines regarding packaging and labeling; advertising, promotion, and sponsorship; public education; cessation; and product testing and disclosure. As well, the Parties agreed to develop financial assistance for the adoption and implementation of the FCTC by countries in need of such assistance. ${ }^{9}$

\section{Forces supporting and opposing development of the FCTC}

The principal factors that contributed to the evolution and eventual adoption of the treaty were the following:

- The clear importance of the public health case concerning smoking and health.

- Research regarding the economic, behavioral, and health impact of smoking and of interventions to reduce smoking.

- A highly effective coalition of Non-Governmental Organizations (NGOs), called the Framework Convention Alliance (FCA). ${ }^{10}$

- Unified regional groups, notably including the continent of Africa.

- A unified response to what was widely perceived to be bullying by the U.S. delegation. (This is discussed below.)
The FCA is particularly worthy of note, given the major role it played in guiding the negotiations toward an evidence-based treaty, as well as its ongoing role in the COPs. The FCA consists of over 200 NGOs from over 100 countries. These organizations include health, consumer, human rights, environmental, and religious groups united to address global tobacco control. The FCA was a powerful voice in the negotiating process that led to development and adoption of the Framework Convention. The alliance provided lobbying and educational sessions throughout the negotiations. Subsequent to the February 2005 official adoption of the treaty, the FCA has assisted countries in developing a strategic plan to encourage them to become Parties to the FCTC. The alliance engages in several monitoring activities as well, monitoring FCTC implementation by Parties at the national level; the status of tobacco and trade agreements (national, regional, and international); and industry behavior in the member countries. Finally, the FCA has assisted with protocol development at the COPs. Throughout all phases of the FCTC process, the FCA has demonstrated remarkable political acuity and unwavering commitment, all the while advocating for evidence-based, best-practice implementation of FCTC measures.

The treaty was not developed without strong opposition. Two major groups fought the development of a strong FCTC. The multinational tobacco companies were prominent in efforts to prevent the development of such a treaty. Similarly, tobacco growers, tobacco product producers, and governments in four countries, all major tobacco or tobacco product producers - the United States, Japan, China, and Germany - tried to water down the strength of the treaty. Throughout the negotiations, the U.S. delegation, in particular, was commonly regarded as a "bully," attempting to throw the country's weight around in an effort to subvert development of a strong treaty. Although the evidence is only anecdotal, many prominent participants in the negotiations credit the U.S. delegation's unsavory methods with creating a unity of purpose among the vast majority of countries that came to Geneva to make important progress in public health.

\section{Policy areas in the FCTC}

The major policy areas considered in the FCTC include the following: advertising and promotion of tobacco products; labeling; taxation; protection against exposure to second-hand smoke; counter marketing; sales practices; cigarette smuggling; product regulation; and legal liability. This section focuses on five of these subjects: 
advertising, labeling, taxation, second-hand smoke, and sales practices. For the specific text regarding each, refer to the FCTC itself. $^{1}$

\section{Advertising and promotion}

With regard to advertising and promotion, the key FCTC provisions called for a complete ban on all advertising and sponsorships, direct and indirect, within five years of ratification of the treaty. Countries that are not permitted constitutionally to ban advertising must restrict it within the limits of their constitutions, including cross border advertising and sponsorships.

The advertising discussion in the negotiations drew on a substantial body of research. That research provides mixed findings on the effects of advertising and promotion, although the weight of the evidence clearly favors a causal connection between advertising and cigarette smoking. ${ }^{11}$ The single best study of the issue concluded that a complete ban on all forms of tobacco advertising and marketing would cause consumption to decline by about 6 percent. ${ }^{12}$ The authors argued that partial bans would be ineffective, however, due to the potential for the industry to substitute a variety of marketing forms for the banned activities.

During the FCTC debate there was little discussion about the effects of advertising. Rather, there was universal acceptance that advertising increased smoking (or at least the proposition went unchallenged during the debate). The major concern focused on the constitutionality of bans in several countries, including the United States. To address the constitutionality issue, negotiators proposed the compromise noted above: countries in which a ban would be unconstitutional would be required to restrict advertising and promotion within the limits of the law. Despite this protection, which covered its own situation, the U.S. rejected the proposal. Ultimately, however, the Convention overrode the objections of the U.S.

\section{Labeling}

The FCTC calls for a rotating warning label covering at least 30 percent of the front and back of every pack of cigarettes. This was a compromise position relative to a stronger provision favored by many delegations. They preferred a requirement that 50 percent of the front and back of packs be dedicated to a warning, with graphic representations of the damage caused by tobacco included. Several countries have adopted such policies or slight variations on them, including Canada and Brazil. The novel labels can be viewed on the Web. ${ }^{13,14}$ There is limited research on the effects of pack warnings, most of it related to the traditional form (i.e., small and poorly placed warnings). That research has produced little evidence of impact. However, new research on Canadian-type labels indicates an impact on smokers' intention to quit smoking and, possibly, on quitting itself. ${ }^{15,16}$

During the negotiations, the debate on labeling focused on practical (political) considerations. Much of the discussion focused on the use of terms like "light" and "low" to describe cigarettes. A wealth of evidence demonstrates that these terms are inaccurate-so-called low tar and nicotine cigarettes can be just as dangerous as "full flavor" cigarettes- and that smokers are misled by them. ${ }^{17}$ Product regulation provisions in the FCTC, not discussed further here, ban the use of misleading descriptive terms like "light" and "low".

\section{Taxation}

Cigarette prices vary dramatically from country to country, ranging from as low as 23 cents per pack to more than $\$ 10 .^{2}$ Table II shows prices of both local brands and Marlboro (or equivalent international brand) in U.S. dollars in several representative countries. The primary factor accounting for the huge price ranges is tax. Among countries for which the data are available, tax varies from 19.7 to $80.4 \%$ of retail price. The FCTC acknowledges that increases in tax and price are highly effective in reducing cigarette consumption. However, the Convention's requirement is much weaker than the importance of taxation would suggest. Countries are merely required to consider health objectives in setting tobacco taxes.

The evidence regarding the impact of taxation constitutes the strongest research base of all tobacco control policies. ${ }^{18}$ In general, a 10 percent increase in cigarette price leads to a 3-4 percent decrease in the quantity of cigarettes demanded by adults in developed countries, as demonstrated in close to 100 studies. ${ }^{19}$ In children and youth in developed nations, the impact of that same 10 percent price increase is on the order of 6-8 percent. This conclusion derives from a much smaller base of research. The same impact $-6-8$ percent-is estimated to apply to adults in less developed countries. While one would expect a more substantial response to increased prices in developing countries, the research supporting this conclusion reflects only a handful of studies. ${ }^{18}$ All told, however, the empirical evidence that increasing price leads to decreasing consumption is so strong that taxation has become a "first principle" of tobacco control policy worldwide.

During the FCTC negotiations, debate regarding taxation focused on the notion of "harmonization," 
Table II

Price of A PACK of Cigarettes IN USD, SELECTED COUNTRIES

\begin{tabular}{lccc} 
Country & Local brand (\$) & $\begin{array}{c}\text { Marlboro } \\
\text { (or equivalent) }\end{array}$ & $\begin{array}{c}\text { Taxes } \% \\
\text { of cigarette price }\end{array}$ \\
Australia & 5.99 & 6.68 & 67.9 \\
\hline Bangladesh & .63 & 1.18 & 65.0 \\
\hline Brazil & .91 & 1.04 & 65.6 \\
\hline Canada & 6.11 & 7.26 & 76.3 \\
\hline China & 1.23 & 1.67 & 38.0 \\
\hline Dominican Republic & .45 & .81 & n.a. \\
\hline Egypt & 1.25 & 1.25 & n.a. \\
\hline France & 5.92 & 6.18 & 80.4 \\
\hline Ghana & .33 & 1.00 & n.a. \\
\hline Iceland & 9.03 & 9.03 & n.a. \\
\hline India & 1.13 & 1.53 & 72.7 \\
\hline Italy & 3.34 & 4.90 & 75.2 \\
\hline Japan & 2.58 & 2.87 & 61.1 \\
\hline Mexico & 1.45 & 1.63 & n.a. \\
\hline Norway & 10.29 & 10.29 & n.a. \\
\hline Panama & 1.20 & 1.20 & n.a. \\
\hline Paraguay & .48 & .71 & n.a. \\
\hline Peru & 1.53 & 1.69 & n.a. \\
\hline Portugal & 2.89 & 3.09 & 77.6 \\
\hline Russia & .85 & 1.50 & 32.9 \\
\hline South Africa & 2.53 & 2.65 & 46.2 \\
\hline Spain & 2.37 & 3.42 & 71.4 \\
\hline Sweden & 5.49 & 5.64 & 69.6 \\
\hline Uhailand & .99 & 1.43 & 60.0 \\
\hline United Kingdom & 9.02 & 9.37 & 78.0 \\
\hline Uruguay & 4.04 & 4.41 & 27.0 \\
\hline Venezuela & 1.17 & 5.07 & 59.0 \\
\hline
\end{tabular}

Source: Mackay et al., Table B. Reference 2

bringing disparate rates across countries within a single region (e.g., Europe) into a consistent pattern. The negotiators were unable to resolve the conflicting concerns regarding harmonization and high taxation. They thus ended up with the aforementioned weak statement that countries must contemplate the health importance of taxation when developing tax policy.

\section{Smoke-free environments}

Currently, nearly a dozen countries ban smoking in virtually all indoor work places, including restaurants and bars. These include Ireland, Italy, Uruguay, Norway, Scotland, Bhutan, New Zealand, Northern Ireland, England, Wales, and France. The FCTC declares it "unequivocally established" that second-hand smoke causes death and disease. It requires parties to adopt "effective ... measures" to protect nonsmokers against exposure in indoor workplaces and indoor public places.

The evidence base for the impact of second-hand smoke is substantial. Well-designed epidemiologic studies conclude that exposure to second-hand smoke (SHS) causes lung cancer in otherwise healthy nonsmokers and contributes significantly to heart disease as well. ${ }^{20}$ With regard to the latter, recent research has found significant decreases in acute myocardial infarctions in communities following their implementation of smoke-free laws. ${ }^{21,22}$ Further, there is ample research demonstrating that bans on smoking in workplaces:

- Dramatically reduce workers' exposures to $\mathrm{SHS}^{23}$

- Increase quitting ${ }^{24}$

- Do not harm business in hospitality industry enterprises ${ }^{25}$

During the FCTC negotiations, there was limited argument about the health effects of second-hand smoke. Delegates did debate, however, how "far" the FCTC should go in addressing the problem of secondhand smoke. There was some sentiment for "restrictions" on smoking in public places -i.e., requiring nonsmoking areas- and there was also much sentiment favoring complete prohibition. Two categories of issues complicated the discussion. The first were philosophical issues concerning "smokers' rights." Second, delegates from countries with federal systems of government expressed concern about requiring a nation-wide law, since their legal systems assign responsibility for such policies to individual states, rather than the federal government. Ironically, while nonsmokers are protected from SHS throughout much of the U.S. (close to 30 states ban smoking in all workplaces including restaurants and $b_{a r s^{2}}$ ), the U.S. delegation was one of the most vociferous opponents of a call for a complete ban, even when a constitutional exception was suggested.

\section{Sales practices}

With regard to sales practices, the FCTC calls for bans on:

- Sales to minors

- Distribution of free samples of tobacco products

- Sales of "loosies" (single cigarettes) 
The Convention suggests, but does not mandate, banning self-service machines and candy cigarettes and making vending machines inaccessible to children.

There is little research on the impact of sales practices. Bans on sales to minors have received the most attention. The research indicates that such bans are effective only if there are very serious penalties and serious, widespread enforcement, conditions that rarely exist. Even with an effective ban on sales directly to children, children find many mechanisms to acquire cigarettes. ${ }^{27}$

During the FCTC, several respected delegations emphasized the importance of banning sales to youth, despite the lack of demonstrated effectiveness supporting the policy. Negotiators expressed little opposition to including it in the Convention. The most compelling argument against such a policy, presented during the negotiations, was that enforcement of it would consume resources that would be better placed in more cost-effective interventions. Ultimately, this argument carried little weight.

\section{The Impact of Evidence on the FCTC}

Evidence-based research played a significant role in the evolution and eventual development of the FCTC. The health effects literature, covering both primary and second-hand smoking, clearly motivated the treaty and many of its strong provisions. Delegates learned a great deal from policy research, especially as it was summarized in a World Bank report, Curving the Epidemic: Governments and the Economics of Tobacco Control, published in 1999..$^{28}$ This volume summarized the research-based findings on the effects of tobacco control policies. It became something of a "bible" during the negotiations leading up to the FCTC. The delegates clearly relied on policy research findings when they supported popular polices in which the research was consistent with the policy preferences of the delegates.

Some of the best examples of research that had a significant impact throughout the negotiations included the following:

- The original epidemiologic studies linking smoking and lung cancer ${ }^{29,30}$

- Research on behavioral and pharmacological approaches to treating smoking ${ }^{31}$

- Research on the effects of second-hand smoke on health ${ }^{20}$
- Research linking tax increases to smoking decreases $^{18}$

The research-based evidence has been incorporated into model legislation for tobacco control, including manuals intended for the use of Convention delegates and their countries. ${ }^{32}$ These in turn have been used to develop national level reports.

Evidence-based research did not always win the day, however. Negative findings from the research literature were often ignored when they were not consistent with delegates' perception of "the right thing to do." Illustrative is the aforementioned nearly universal support for bans on sales to minors. In short, and as would be expected, political considerations often ruled the day.

\section{Conclusion}

Implementation of the FCTC in the 150-plus countries that have ratified faces several obstacles. ${ }^{33}$ These include:

- Inadequate in-country research talent. There are relatively few countries in which there are researchers active in the field of tobacco control research.

- Inadequate financial institutional resources to support implementation of the FCTC.

- Alack of political will and, frankly, interest in many countries.

- Political and economic opposition, led by the powerful tobacco industry in many countries.

If significant progress can be made in combating smoking, the benefits will be enormous. Consider that if youth taking up smoking could be cut in half, 20 million deaths from tobacco-related diseases would be prevented worldwide by 2050. If adult consumption could be halved, 30 million deaths would be prevented by 2025 . Further, fully 150 million deaths would be prevented by the middle of this century. ${ }^{28}$

Few issues are as important in public health as grappling with the epidemic of tobacco-produced disease. The Framework Convention on Tobacco Control constitutes the first global weapon with which to make a serious attempt to reduce this remarkably devastating man-made source of death and misery. 


\section{References}

I. World Health Organization. WHO Framework Convention on Tobacco Control (WHO FCTC) http://www.who.int/tobacco/framework/ en/ <accessed December 12, 2007>.

2. Mackay J, Eriksen M, Shafey O. The Tobacco Atlas. $2^{\text {nd }}$ edition. Atlanta: American Cancer Society, 2006.

3. American Cancer Society. Tobacco control country profiles: Mexico, 2003. http://www.who.int/tobacco/media/en/Mexico.pdf <accessed December 13, 2007>.

4. World Health Organization. Building blocks for tobacco control: A handbook. Geneva: WHO, 2004. http://www.who.int/tobacco/resources/ publications/general/HANDBOOK\%20Lowres\%20with\%20cover.pdf <accessed December 13, 2007>.

5. Department of Health and Human Services. The health consequences of smoking: a report of the surgeon general. Centers for Disease Control and Prevention, National Center for Chronic Disease Prevention and Health Promotion, Office on Smoking and Health. Washington (D.C.): U.S. G.P.O., 2004

6. Lopez AD, Collishaw NE, Piha T. A descriptive model of the cigarette epidemic in developed countries. Tob Control 1994;3:242-247.

7. World Health Organization. WHO Framework Convention on Tobacco Control. Article 3, 2003. http://www.who.int/tobacco/framework/WHO_ FCTC_english.pdf <accessed December 13, 2007>.

8. World Health Organization. The first session of the Conference of the Parties to the WHO Framework Convention on Tobacco Control, 2007. http://www.who.int/tobacco/fctc/cop/en/ <accessed December 13, 2007>. 9. World Health Organization. Conference of the Parties to the WHO Framework Convention on Tobacco Control, 2007. http://www.who. int/gb/fctc/E/E_cop2.htm <accessed December 13, 2007>.

10. Framework Convention Alliance, 2007. http://www.fctc.org/ <accessed December |3, 2007>.

II. U.S. Department of Health and Human Services. Reducing the health consequences of smoking: 25 years of progress. A report of the Surgeon General. Public Health Service, Centers for Disease Control, National Center for Chronic Disease Prevention and Health Promotion, Office on Smoking and Health. DHHS Publication No. (CDC), 1989;89-84II. 12. Saffer $\mathrm{H}$, Chaloupka $\mathrm{F}$. The effect of tobacco advertising bans on tobacco consumption. J Health Econ 2000;19:1 I 17- I 37.

13. Health Canada. Health warning labels for consumer tobacco products, 2007. http://www.hc-sc.gc.ca/ahc-asc/media/photogal/label-etiquette/ index_e.html <accessed December 13, 2007>.

14. Tobacco Control Supersite. Picture gallery - cigarette packs and graphical cigarette pack warnings, 2007. http://tobacco.health.usyd.edu. au/site/supersite/resources/docs/gallery_packwarnings.htm <accessed December |3, 2007>.

15. Hammond D, Fong GT, McDonald PW, Cameron R, Brown KS. Impact of the graphic Canadian warning labels on adult smoking behaviour. Tob Control 2003;12:391-395.

16. Hammond D, Fong GT, McNeill A, Borland R, Cummings KM. Effectiveness of cigarette warning labels in informing smokers about the risks of smoking: Findings from the International Tobacco Control (ITC) Four Country Survey. Tob Control 2006; I5(Suppl 3 ):iii I9-iii25.
17. National Cancer Institute. Risks associated with smoking cigarettes with low machine-measured yields of tar and nicotine. Smoking and Tobacco Control Monograph I3. National Institutes of Health, Public Health Service, Department of Health and Human Services, 200I. http://cancercontrol.cancer.gov/tcrb/monographs/I3/m/3_complete.pdf <accessed December 13, 2007>.

18. Chaloupka FJ, Hu TW, Warner KE, Jacobs R, Yurekli A. In: Jha P, Chaloupka F, eds. Tobacco control in developing countries. New York: Oxford University Press, 2000.

19. Gallet CA, List JA. Cigarette demand: A meta-analysis of elasticities. Health Econ 2003;12:821-835.

20. U.S. Department of Health and Human Services. The health consequences of involuntary exposure to tobacco smoke: A report of the Surgeon General-executive summary. Centers for Disease Control and Prevention, Coordinating Center for Health Promotion, National Center for Chronic Disease Prevention and Health Promotion, Office on Smoking and Health, 2006.

21. Dinno A, Glantz S. Clean indoor air laws immediately reduce heart attacks. Prev Med 2007;45:9-1I.

22. Juster HR, Loomis BR, Hinman TM, Farrelly MC, Hyland A, Bauer UE, et al. Declines in hospital admissions for acute myocardial infarction in New York State after implementation of a comprehensive smoking ban. Am J Public Health 2007;97:2035-2039.

23. Goodman P, Agnew M, McCaffrey M, Paul G, Clancy L. Effects of the Irish smoking ban on respiratory health of bar workers and air quality in Dublin pubs. Am J Respir Crit Care Med 2007; 175:75I-753.

24. Fichtenberg CM, Glantz SA. Effect of smoke-free workplaces on smoking behaviour: Systematic review. BMJ 2002;325:188-195.

25. Alpert HR, Carpenter CM, Travers MJ, Connolly G. Environmental and economic evaluation of the Massachusetts Smoke-Free Workplace Law. J Community Health 2007;32:269-28I.

26. American Nonsmokers' Rights Foundation. Summary of $100 \%$ smokefree state laws and population protected by $100 \%$ U.S. smokefree laws, 2007. http://www.no-smoke.org/pdf/SummaryUSPopList.pdf <accessed December |4, 2007>.

27. Stead LF, Lancaster T. Interventions for preventing tobacco sales to minors. Cochrane Database of Systematic Reviews 2005; (I):CD00I 497. 28. World Bank. Curbing the epidemic: Governments and the economics of tobacco control. Washington: World Bank, 1999

29. Wynder EL, Graham EA. Tobacco smoking as a possible etiologic factor in bronchiogenic carcinoma: A study of 684 proved cases. JAMA 1950; 143:329-396.

30. Doll $R$, Hill $A B$. The mortality of doctors in relation to their smoking habits: A preliminary report. BMJ 1954; I: I 45 I- I 455.

3I. Fiore MC, Bailey WC, Cohen SJ, Dorfman, SF, Goldstein, MG, Gritz, ER. Treating tobacco use and dependence. Clinical practice guideline. U.S. Department of Health and Human Services, Public Health Service, 2000. http://www.surgeongeneral.gov/tobacco/treating_tobacco_use.pdf <accessed December 15, 2007>.

32. Nathan R. Model legislation for tobacco control: A policy development and legislative drafting manual. Saint-Denis, France: International Union for Health Promotion and Education, 2004.

33. Warner KE. The role of research in international tobacco control. Am J Public Health 2005;95:976-984. 